\title{
Difference in vertical jumping abilities, endurance and quickness of regeneration lower extremity muscle groups after physical effort between CrossFit and climbing athletes
}

\begin{abstract}
Introduction. Productive sporting performance in various sports disciplines often heavily depends on jumping abilities as well as on lower limb muscles power and endurance of the athletes involved. Both CrossFit, a popular high-intensity training program and sport climbing require lower extremity muscular power and endurance.

Aim. The aim of this study was to compare vertical jumping abilities, endurance and quickness of the regeneration in gastrocnemius lateralis (GL), vastus medialis (VMO) and gluteus maximus (GM) muscles in CrossFit athletes and sport climbers.

Material and methods. The study comprised 20 male athletes aged $24.3 \pm 4.7$, divided into two equal groups: training CrossFit (CF) and sport climbers (SC). Vertical jump test was recorded by Vicon ${ }^{\circledR}$ motion capture system and AMTI ${ }^{\circledR}$ biomechanics force platforms. The myoelectric activity of the GL, VMO and GM muscles was recorded by myon ${ }^{\circledR}$.

Results. Significant difference in height of vertical jump in CrossFit athletes and sport climbers was observed (SC: $125.43 \mathrm{~cm}$, $120.92 \mathrm{~cm}$; CF: $110.42 \mathrm{~cm}, 110.86 \mathrm{~cm} ; \mathrm{p}<0.05)$. The endurance of the GL muscles in athletes using CrossFit training is significantly higher in comparison to sport climbers. Athletes training CrossFit have a better ability to recover GL, GM and VMO muscles than sport climbers.

Conclusions. Sport climbers have better results in vertical jump tests than the athletes doing CrossFit. The endurance of the GL muscles in athletes doing CrossFit is higher in comparison to sport climbers. Athletes doing CrossFit have also better ability to muscles recover than sport climbers.
\end{abstract}

Keywords: athletes, CrossFit, sport climbing, surface electromyography, 3D motion capture.

DOI: $10.1515 /$ pjph-2017-0036

\section{INTRODUCTION}

Vertical jump is a plyometric move where all three extensor moments of force (hip extension, knee extension and ankle plantarflexion) are involved [1]. Vertical jump requires a combination of strength, speed, and power of muscles involved in hip extension (gluteus maximus), knee extension (the quadriceps femoris) and ankle plantarflexion (gastrocnemius) [1-3].

CrossFit, a high-intensity training is a fast growing sport activity, but only little research on this exercise system has been performed to date [4]. CrossFit workouts is a less than 30 minutes duration training with high - intensity exercise program, consisting mainly of a mix of aerobic exercises and body weight exercises [5,6]. Training program via CrossFit improves maximal oxygen uptake, metabolic capacity, and body composition [7]. CrossFit makes use of a wide variety of power lifting exercises (squat, deadlift), and gymnastic movements (toes-to-bar, knees-to-elbows, lunges, burpees, gluteus-hamstring developer sit-ups, pistols) for lower extremity muscular strength and endurance [8].
Sport climbing has increased in popularity as a recreational physical activity and competitive sport. It has a positive effect on strength and endurance development of the human muscular system [9]. Many studies during the last few decades have focused on general upper-limb strength in sport climbers [10-12]. Limited research has been conducted on lower extremity muscles work during sport climbing [13,14]. Sport climbing requires more upper than lower limb strength, but with good technique, most of the power should come from the lower body, with the upper body providing the ability to balance and stay close to the wall [15-17]. Speed climbing requires dynamic moves that send climbers flying through the air to get to a hold that is otherwise out of reach. Strong lower extremity muscles will increase push off speed from the hold, lengthen reach dynamically and improve speed and quality of climbing. Sport climbing requires both strength and endurance to climb long routes in rock and to compete. Climbing abilities, despite the tiredness caused by a long climb, must be kept on a steady level, in order to pass through the climbing route.

\footnotetext{
${ }^{1}$ Chair and Department of Rehabilitation, Physiotherapy and Balneotherapy, Medical University of Lublin, Poland

${ }^{2}$ Institute of Computer Science, Electrical Engineering and Computer Science Faculty, Lublin University of Technology, Poland

${ }^{3}$ Medical Students' Research Association of the Medical University of Lublin, Poland
} 
Motion capture system is a non-invasive method for recording human movements [18-20]. Biomechanics Force Platforms can be used to collect kinetic data relating to ground reaction forces by detecting forces and moments applied to their top surface $[21,22]$. By the set of marker motion detection cameras, objective assessment and analysis of a competitor in space is possible, while performing specialized training activities, such as vertical jump. Muscle activity is studied during isometric exercises using surface electromyograms (sEMG) in time domain and allows for non-invasive examination of muscle fatigue during isometric exercises. The analysis of frequency provides information that is important to understand fatigue process [23]. The symptom of muscle fatigue during isometric contraction is decrease in spectral median frequency at the final of exercise [23-25]. Coordinated functioning of motion capture system, biomechanics force platforms and sEMG system allows objective comparison of the competitors' sport skills.

\section{AIM}

The aim of this study was to compare vertical jumping abilities, endurance and quickness of the regeneration in gastrocnemius lateralis (GL), vastus medialis (VMO) and gluteus maximus (GM) muscles during isometric exercises in CrossFit athletes and sport climbers.

\section{MATERIAL AND METHOD}

\section{ETHICS STATEMENT}

This study was approved by the ethical committee of Medical University of Lublin, Poland (KE-0254/331/2015). All sportsmen were informed about the procedures they would undergo and gave their informed consent to participate in the tests.

\section{SUBJECT DESCRIPTION}

The study comprised 20 male athletes with a dominant right leg, practicing CrossFit and sport climbing since two years 3 times a week in a sports club. The dominant leg was determined by asking the subjects which leg they would choose to kick a ball [26]. The study subjects were divided into two equal groups, i.e. 10 athletes in each group: training CrossFit (CF; age: $24.4 \pm 3.2$ years; height: $174.2 \pm 5.2 \mathrm{~cm}$; body weight: $66.2 \pm 6.1 \mathrm{~kg}$ ) and sport climbing (SC; age: $25.1 \pm 4.5$ years; height: $173.6 \pm 5.8 \mathrm{~cm}$; body weight: $64.5 \pm 4.8 \mathrm{~kg}$ ). During a six-month period prior to the study, all of the study subjects were in good state of health, without any conditions, which could influence the result of the test. All the tests were conducted in the morning to decrease the influence of the variability of bioelectrical activity of the muscle. The test performers were weighed before measurement without shoes and with minimal clothing. All the athletes were informed about the course of the measurements and agreed to participate in the tests.

\section{THE 3D DYNAMIC MEASUREMENT (VERTICAL JUMP TEST)}

Dynamic measurement (vertical jump test) was recorded using a Vicon optical motion capture system equipped with eight NIR T40S cameras. The Vicon Nexus 2.0 was used for 3D kinematic data collection (sampled at $100 \mathrm{~Hz}$ ) and postprocessing. The kinetics data was measured using two AMTI
Biomechanics Force Platforms. Motion capture system and force platforms were synchronized and calibrated prior to testing. Using palpation method reflecting marker was attached on the processus spinosus of L3.

\section{THE SEMG MEASUREMENT (ISOMETRIC TEST)}

The 16-channel modular Wi-Fi myon EMG system, compatible with myon ProEMG software, was used for the recording. The surface electrodes $(\mathrm{Ag} / \mathrm{AgCl})$ were distributed to the muscle fibre direction of GL, VMO, GM of the right lower extremity with the reference electrode on the patella. The measurement was compiled from SENIAM standards. The skin under the electrodes was cleaned with alcohol.

\section{MEASUREMENT PLAN}

Prior to data collection, each athlete performed a $10 \mathrm{~min}$ utes dynamic warm-up including vertical jumps. After warmup, athletes performed four tasks: first vertical jump (FVJ), first isometric test (FIT), second vertical jump (SVJ) and second isometric test (SIT). All 4 tasks were measured without shoes and with minimal clothing.

The athletes were instructed to perform a two-foot vertical jump (FVJ), that each foot was contacted one various platform separately and fully (Figure 1). While in the next condition (FIT), the athletes were asked to assume a half knee bend position for 60 seconds (knees bent at a $90^{\circ}$, hips bent at a $60^{\circ}$, hands laced). After a 2 minutes recovery period, athletes performed a two-foot vertical jump (SVJ) and 60 seconds isometric test in half knee bend position (SIT).

During vertical jump test (FVJ and SVJ), the reflecting maker (processus spinosus of L3) movement and force plate data were recorded. Height of vertical jump was estimated using a biomechanical model based on data acquired by the motion capture. The height of each jump was taken from the displacement of the processus spinosus of L3 (the highest vertical position minus vertical position before the onset of the movement) [27]. Force plate data (maximum ground reaction force - MGRF) were normalized to body mass (\% BM) and calculated for all the participants $[21,28,29]$.

During isometric test (FIT and SIT), the electrical activity of the GL, VMO and GM muscles of the right and left lower limbs was recorded. Spectral median frequency (MF) was compared between the beginning second and the final second of tests. The dynamics of the MF during whole test was obtained by short-time Fourier transform.

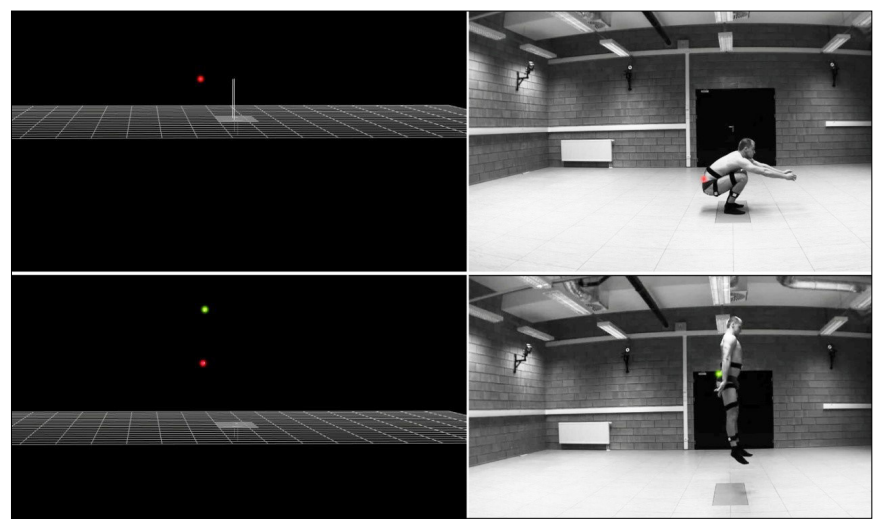

FIGURE 1. Dynamic FVJ and SVJ measurement (vertical jump test). 


\section{Data analysis}

IBM SPSS STATISTICS programme was used to prepare the statistical analysis. To compare the variables between the four conditions (FVJ, FIT, SVJ, SIT), T- test paired - samples and T- test independent samples were used. Differences were regarded as statistically significant if the level of probability value was lower than the statistical significance $(\mathrm{p}<0.05)$.

\section{RESULTS}

\section{CHARACTERISTICS OF GROUPS}

The characteristics of groups analysis did not show any significant difference ( $p>0.05)$ in age, height and body weight between CrossFit and Climbing athletes (Table 1).

TABLE 1. Average $( \pm$ SD) age, height and body weight in CrossFit athletes and sport climbers.

\begin{tabular}{lcccccc}
\hline \hline \multicolumn{1}{c}{ Group } & n & Male & Female & $\begin{array}{c}\text { Age } \\
(\text { years) } *\end{array}$ & $\begin{array}{c}\text { Height } \\
(\mathbf{c m}) *\end{array}$ & $\begin{array}{c}\text { Body weight } \\
(\mathbf{k g}) *\end{array}$ \\
\hline CrossFit & 10 & 10 & 0 & $24.4 \pm 3.2$ & $174.2 \pm 5.2$ & $66.2 \pm 6.1$ \\
\hline $\begin{array}{l}\text { Sport } \\
\text { climbing }\end{array}$ & 10 & 10 & 0 & $25.1 \pm 4.5$ & $173.6 \pm 5.8$ & $64.5 \pm 4.8$ \\
\hline
\end{tabular}

* no significant differences between groups $(\mathrm{p}>0.05)$

\section{VERTICAL JUMPING ABILITIES (FVJ AND SVJ MEASUREMENT)}

The height of vertical jump was greater in sport climbers (SC) in both measurements (FVJ: 125.43 \pm 7.47 , SVJ: 120.92 \pm 7.64) than in athletes doing CrossFit (CF) (FVJ: 110.42 \pm 7.74, SVJ: 110.86 \pm 7.22) (Table 2).

TABLE 2. The height of vertical jump during FVJ and SVJ in CrossFit athletes and sport climbers.

\begin{tabular}{|c|c|c|c|c|c|c|}
\hline Measurement & Group & $\mathbf{n}$ & $\begin{array}{c}\text { Mean jump height } \\
(\mathrm{cm})\end{array}$ & SD & $\mathbf{t}$ & $\mathbf{p}$ \\
\hline \multirow{2}{*}{ FVJ } & $\mathrm{CF}$ & 10 & 110.42 & 7.74 & \multirow{2}{*}{-4.41} & \multirow{2}{*}{$0.001^{*}$} \\
\hline & $\mathrm{SC}$ & 10 & 125.43 & 7.47 & & \\
\hline \multirow{2}{*}{ SVJ } & $\mathrm{CF}$ & 10 & 110.86 & 7.22 & \multirow{2}{*}{-3.03} & \multirow{2}{*}{$0.007^{*}$} \\
\hline & $\mathrm{SC}$ & 10 & 120.92 & 7.64 & & \\
\hline
\end{tabular}

* significant differences between groups $(\mathrm{p}<0.05)$

In CrossFit athletes the analysis did not show any significant difference in height of vertical jump between FJV and SVJ conditions (mean difference:- $0.44 \mathrm{~cm} ; \mathrm{p}>0.05$ ) in comparison to athletes training sport climbing (mean difference: $4.51 \mathrm{~cm} ; \mathrm{p}<0.05$ ) (Table 3).

TABLE 3. Difference in height of vertical jump between FVJ and SVJ in CrossFit athletes and sport climbers.

\begin{tabular}{|c|c|c|c|c|c|}
\hline Group & Measurement & $\mathbf{n}$ & $\begin{array}{l}\text { Mean jump height } \\
(\mathrm{cm})\end{array}$ & $\begin{array}{c}\text { Mean } \\
\text { differences }\end{array}$ & $\mathbf{p}$ \\
\hline \multirow{2}{*}{$\mathrm{CF}$} & FVJ & 10 & 110.42 & \multirow{2}{*}{-0.44} & \multirow{2}{*}{0.289} \\
\hline & SVJ & 10 & 110.86 & & \\
\hline \multirow{2}{*}{$\mathrm{SC}$} & FVJ & 10 & 125.43 & \multirow{2}{*}{4.51} & \multirow{2}{*}{$0.002 *$} \\
\hline & SVJ & 10 & 120.92 & & \\
\hline
\end{tabular}

* significant differences between groups $(\mathrm{p}<0.05)$
The maximum ground reaction force of non-dominant leg was significantly greater in sport climbers in both measurements in comparison to dominant leg (significant differences only in FVJ) (Table 4).

TABLE 4. Difference in maximum ground reaction force between CrossFit athletes and sport climbers.

\begin{tabular}{|c|c|c|c|c|c|c|c|}
\hline \multirow{2}{*}{ Measurement } & \multirow{2}{*}{ Group } & \multicolumn{3}{|c|}{ Dominant leg } & \multicolumn{3}{|c|}{ Non-dominant leg } \\
\hline & & Mean & SD & $\mathbf{t}$ & Mean & SD & $\mathbf{t}$ \\
\hline \multirow{2}{*}{ FVJ } & $\mathrm{CF}$ & 89.80 & 5.91 & \multirow{2}{*}{$-2.40 *$} & 93.78 & 6.07 & \multirow{2}{*}{$-4.57 *$} \\
\hline & $\mathrm{SC}$ & 97.44 & 8.14 & & 111.52 & 10.68 & \\
\hline \multirow{2}{*}{ SVJ } & $\mathrm{CF}$ & 88.16 & 5.90 & \multirow{2}{*}{-1.99} & 92.68 & 5.51 & \multirow{2}{*}{$-3.73 *$} \\
\hline & $\mathrm{SC}$ & 94.95 & 9.06 & & 104.86 & 8.73 & \\
\hline
\end{tabular}

* significant differences between groups $(\mathrm{p}<0.05)$

In relation to the first and the second vertical jump, maximum ground reaction force in SVJ was significantly lower in sport climbers in dominant and non-dominant leg in comparison to CrossFit athletes (significant differences only in dominant leg) (Table 5).

TABLE 5. Maximum ground reaction force in relation to the first and the second vertical jump in CrossFit athletes and sport climbers.

\begin{tabular}{|c|c|c|c|c|c|c|c|}
\hline \multirow[t]{2}{*}{ Group } & \multirow[t]{2}{*}{ Leg } & \multicolumn{2}{|c|}{$\begin{array}{c}\text { FVJ MGRF } \\
\text { (\% body } \\
\text { mass) }\end{array}$} & \multicolumn{2}{|c|}{$\begin{array}{c}\text { SVJ MGRF } \\
\text { (\% body } \\
\text { mass) }\end{array}$} & \multirow[t]{2}{*}{$\begin{array}{l}\text { FVJ-SVJ } \\
\text { mean } \\
\text { differences }\end{array}$} & \multirow[t]{2}{*}{$\mathbf{p}$} \\
\hline & & Mean & SD & Mean & SD & & \\
\hline \multirow{2}{*}{ CrossFit } & $\begin{array}{l}\text { Dominant } \\
\text { leg }\end{array}$ & 89.80 & 5.91 & 88.16 & 5.90 & 1.64 & $0.011^{*}$ \\
\hline & $\begin{array}{c}\text { Non-dominant } \\
\text { leg }\end{array}$ & 93.78 & 6.07 & 92.68 & 5.51 & 1.1 & 0.155 \\
\hline \multirow{2}{*}{$\begin{array}{l}\text { Sport } \\
\text { climbing }\end{array}$} & Dominant leg & 97.44 & 8.14 & 94.95 & 9.06 & 2.49 & $0.001 *$ \\
\hline & $\begin{array}{c}\text { Non-dominant } \\
\text { leg }\end{array}$ & 111.52 & 10.68 & 104.86 & 8.73 & 6.66 & $0.001^{*}$ \\
\hline
\end{tabular}

* significant differences between groups $(\mathrm{p}<0.05)$

\section{MUSCULAR ENDURANCE (FIT AND SIT MEASURE- MENT)}

The significant decrease in spectral median frequency of GL muscles was greater in sport climbers only during FIT measurement. During SIT measurement, the significant decrease in spectral median frequency of GL and GM muscles was greater in sport climbers than in athletes getting CrossFit training (Table 6).

In CrossFit athletes the analysis did not show any significant difference in spectral median frequency GL, GM and VMO muscles between FIT and SIT conditions in comparison to athletes training sport climbing (significant differences in spectral median frequency GL, GM and VMO muscles) (Table 7). 
TABLE 6. Difference in spectral median frequency (MF), the electrical activity of the GL, GM and VMO muscles (average \% left and right limb) between CrossFit athletes and Sport climbers in FIT and SIT measurement.

\begin{tabular}{|c|c|c|c|c|c|c|c|c|c|c|c|c|}
\hline \multirow{2}{*}{ Measurement } & \multicolumn{4}{|c|}{ GL } & \multicolumn{4}{|c|}{ GM } & \multicolumn{4}{|c|}{ VMO } \\
\hline & CF (\%) & SC (\%) & $\mathbf{t}$ & $\mathbf{p}$ & CF (\%) & SC (\%) & $\mathbf{t}$ & $\mathbf{p}$ & CF (\%) & SC (\%) & $\mathbf{t}$ & $\mathbf{p}$ \\
\hline FIT & 5.12 & 7.35 & -2.69 & $0.02 *$ & 6.37 & 7.89 & -2.10 & 0.051 & 12.91 & 11.72 & 0.34 & 0.34 \\
\hline SIT & 5.70 & 9.35 & -4.59 & $0.01 *$ & 6.39 & 9.64 & -4.32 & $0.001 *$ & 13.44 & 14.66 & -1.07 & 0.30 \\
\hline
\end{tabular}

* significant differences between groups $(\mathrm{p}<0.05)$

TABLE 7. Percentage change of spectral median frequency (MF), the electrical activity of the GL, GM and VMO muscles (average \% left and right limb) between the beginning, the second and the final second of tests in FIT and SIT measurement.

\begin{tabular}{|c|c|c|c|c|c|c|c|c|}
\hline \multirow[t]{2}{*}{ Group } & \multicolumn{2}{|c|}{$\begin{array}{c}\text { FIT Mean MF (\%) } \\
\pm \text { SD }\end{array}$} & \multicolumn{3}{|c|}{$\begin{array}{c}\text { SIT Mean MF (\%) } \\
\pm \text { SD }\end{array}$} & \multicolumn{3}{|c|}{$\begin{array}{c}\text { FIT - SIT Mean } \\
\text { MF difference }(\%) \\
\text { p }\end{array}$} \\
\hline & GM & VMO & GL & GM & VMO & GL & GM & VMO \\
\hline \multirow{2}{*}{$\mathrm{CF}$} & 6.37 & 12.91 & 5.70 & 6.39 & 13.44 & 0.59 & 0.02 & 0.52 \\
\hline & $\pm 2.10 \pm 1.46$ & \pm 2.50 & \pm 1.98 & \pm 1.37 & \pm 2.84 & $\mathrm{p}=0.3$ & $\mathrm{p}=0.95$ & $\mathrm{p}=0.19$ \\
\hline \multirow{2}{*}{$\mathrm{SC}$} & 7.35 & 11.72 & 9.35 & 9.64 & 14.66 & $2.00^{*}$ & $1.76^{*}$ & $2.95^{*}$ \\
\hline & $\pm 1.57 \pm 1.76$ & \pm 2.93 & \pm 1.55 & \pm 1.95 & \pm 2.25 & $\mathrm{p}=0.001$ & $\mathrm{p}=0.001$ & $\mathrm{p}=0.001$ \\
\hline
\end{tabular}

* significant differences between groups $(\mathrm{p}<0.05)$

\section{DISCUSSION}

The main aim of this study was to compare vertical jumping abilities, endurance and quickness of regeneration in gastrocnemius lateralis (GL), vastus medialis (VMO) and gluteus maximus (GM) muscles during the isometric exercises in athletes training CrossFit and sport climbing. Productive sporting performance in sport climbing depends heavily on the jumping abilities of the athletes involved.

The vertical jump requires a combination of strength, speed, and power of muscles involved in hip extension (gluteus maximus), knee extension (the quadriceps femoris) and ankle plantarflexion (gastrocnemius) [1,2]. Sport climbers have better results in vertical jump tests (height, maximum ground reaction force) than athletes doing CrossFit. It may be caused by the fact that sport climbing training may increase vertical jump abilities through speed climbing and dynamic moves that send climbers flying through the air to get to a hold that is otherwise out of reach. However, tiredness causes decrease of jump height and ground reaction forces of sport climbers, in comparison to CrossFit athletes (Table 3, Table 5). The results of our research suggest that the decrease of jump height and maximum ground reaction force of sport climbers after physical effort may be related to lower endurance of muscles engaged in vertical jump and to worse recuperation skills of the sport climbers' muscles.

Tiredness does not lower significantly the height of jump and ground reaction force of CrossFit athletes (Table 3, Table 5). It may be related to the fact that the endurance of the GL muscles in CrossFit athletes is significantly higher in comparison to sport climbers and CrossFit athletes have a better ability to recover after physical effort than sport climbers within the muscle groups GL, GM and VMO (FIT measurement, Tab. 6; FIT - SIT mean MF difference, Table 7). CrossFit training improved maximal oxygen uptake and metabolic capacity thanks to high-intensity exercise program, consisting mainly of aerobic exercises and wide variety of power lifting exercises (squat, deadlift), and gymnastic movements (toes-to-bar, knees-to-elbows, lunges, burpees, gluteus-hamstring developer sit-ups, pistols) [7]. The use of the aforementioned exercises may significantly influence endurance of GM, GL and VMO muscles and regeneration of muscle groups after physical effort. CrossFit training focuses on the build of force endurance of lower limbs, therefore it may increase the pace of the muscles' recuperation. The use of CrossFit in sport climbing may increase the skill of jumping in the condition of tiredness through the improvement of the tested muscle endurance, and may influence the quality of climbing. The influence of CrossFit training performed by sport climbers on the endurance and recuperation of muscle groups of lower limbs, and on vertical jump abilities after physical effort requires further research.

\section{CONCLUSIONS}

1. Sport climbers have better results in vertical jump tests (height, maximum ground reaction force) than athletes doing CrossFit.

2. The endurance of the GL muscles in athletes doing CrossFit is significantly higher in comparison to athletes training sport climbing.

3. Athletes doing CrossFit have a better ability to recover GL, GM and VMO muscles after isometric effort in half knee bend position between FIT and SIT measurement than sport climbers.

\section{REFERENCES}

1. Robertson DG, Fleming D. Kinetics of standing broad and vertical jumping. Can J Sport Sci. 1987;12(1):19-23.

2. Aragón-Vargas LF, Gross MM. Kinesiological limits of vertical jump performance: differences among individuals. Med Sci Sports Exerc. 1995;27:170.

3. Ford KR, Myer GD, Brent JL, Hewett TE. Hip and knee extensor moments predict vertical jump height in adolescent girls. J Strength Cond Res. 2009;23(4):1327-31.

4. Bellar D, Hatchett A, Judge LW, et al. The relationship of aerobic capacity, anaerobic peak power and experience to performance in CrossFit exercise. Biol Sport. 2015;32(4):315-20.

5. Hak PT, Hodzovic E, Hickey B. The nature and prevalence of injury during CrossFit training. J Strength Cond Res. 2013;22. DOI: 10.1519/ JSC.0000000000000318.

6. Kliszczewicz B, Quindry CJ, Blessing LD, et al. Acute exercise and oxidative stress: CrossFitTM vs. Treadmill Bout. J Hum Kinet. 2015;47:81-90.

7. Smith MM, Sommer AJ, Starkoff BE, Devor ST. Crossfit-based high-intensity power training improves maximal aerobic fitness and body composition. J Strength Cond Res. 2013;27(11):3159-72.

8. Weisenthal BM, Beck CA, Maloney MD, et al. Injury rate and patterns among CrossFit athletes. Orthop J Sports Med. 2014;2(4):2325967114531177.

9. Ginszt M, Goniewicz M, Ginszt A, Goniewicz K. Climbing injuries among children and youth. Perfekta Info. 2011:137-45.

10. Laffaye G. Determinant factors in climbing ability: influence of strength, anthropometry and neuromuscular fatigue. Scand J Med Sci Sports. 2016;26(10):1151-9

11. Laffaye G, Collin J-M, Levernier G, Padulo J. Upper-limb power test in rock-climbing. Int J Sports Med. 2014;35(8):670-5.

12. MacLeod D, Sutherland DL, Buntin L, et al. Physiological determinants of climbing-specific finger endurance and sport rock climbing performance. J Sports Sci. 2007;25(12):1433-43 
13. Stern JT, Paré EB, Schwartz JM. New perspectives on muscle use during locomotion: electromyographic studies of rapid and complex behaviors. J Am Osteopath Assoc. 1980;80(4):287-91.

14. Bartlett JL, Sumner B, Ellis RG, Kram R. Activity and functions of the human gluteal muscles in walking, running, sprinting, and climbing. Am J Phys Anthropol. 2014;153(1):124-31.

15. Horst E. Maximum climbing: mental training for peak performance and optimal experience. Guilford: Rowman \& Littlefield; 2010.

16. Campbell AD, Davis C, Paterson R, et al. Preparticipation evaluation for climbing sports. Clin J Sport Med. 2015;25(5):412-7.

17. Ginszt M, Goniewicz M, Ginszt A. Analysis of causes and consequences of injuries among children and youth in sport climbing. Hygeia Public Health. 2012;47(1):23-7.

18. Oh H, Cha G, Oh S. Samba: A real-time motion capture system using wireless camera sensor networks. Sensors. 2014;14(3):5516-35.

19. Van Daele U, Huyvaert S, Hagman F, et al. Reproducibility of postural control measurement during unstable sitting in low back pain patients. BMC Musculoskelet Disord. 2007;8(1):44.

20. Etnoyer J, Cortes N, Ringleb SI, et al. Instruction and jump-landing kinematics in college-aged female athletes over time. J Athl Train. 2013;48(2):161-71.

21. Daneshjoo A, Abu Osman NA, Sahebozamani M, Yusof A. Analysis of jumping-landing manoeuvers after different speed performances in soccer players. PLoS ONE. 2015;10(11):e0143323.

22. Krafft FC, Eckelt M, Köllner A, et al. Reproducibility of spatio-temporal and dynamic parameters in various, daily occurring, turning conditions. Gait Posture. 2015;41(1):307-12.
23. Mello RGT, Carri IR, da Matta TT, et al. Lumbar multifidus and erector spinae electromyograms during back bridge exercise in time and frequency domains. J Back Musculoskelet Rehabil. 2016;29(1):123-33.

24. Niederer D, Vogt L, Pippig T, et al. Local muscle fatigue and 3D kinematics of the cervical spine in healthy subjects. J Mot Behav. 2015;16:1-9.

25. Rainoldi A, Falla D, Mellor R, et al. Myoelectric manifestations of fatigue in vastus lateralis, medialis obliquus and medialis longus muscles. J Electromyogr Kinesiol. 2008;18(6):1032-7.

26. Van Lunen BL, Roberts J, Branch JD, Dowling EA. Association of menstrual-cycle hormone changes with anterior cruciate ligament laxity measurements. J Athl Train. 2003;38(4):298-303.

27. Tessier J-F, Basset F-A, Simoneau M, Teasdale N. Lower-limb power cannot be estimated accurately from vertical jump tests. J Hum Kinet. 2013;38:5-13.

28. Wannop JW, Worobets JT, Stefanyshyn DJ. Normalization of ground reaction forces, joint moments, and free moments in human locomotion. J Appl Biomech. 2012;28(6):665-76.

29. Kimura Y, Ishibashi Y, Tsuda E, Yamamoto Y, Hayashi Y, Sato S. Increased knee valgus alignment and moment during single-leg landing after overhead stroke as a potential risk factor of anterior cruciate ligament injury in badminton. Br J Sports Med. 2012;46(3):207-13.

30. McCann MR, Flanagan SP. The effects of exercise selection and rest interval on postactivation potentiation of vertical jump performance. J Strength Cond Res. 2010;24(5):1285-91.

31. Morrison AB, Schöffl VR. Physiological responses to rock climbing in young climbers. Br J Sports Med. 2007;41(12):852-61.

\section{Corresponding author}

Dr Michał Ginszt

Chair and Department of Rehabilitation, Physiotherapy and Balneotherapy Medical University of Lublin

2 Magnoliowa St., 20-143 Lublin, Poland

tel.: +48602533723

E-mail: michal.ginszt@umlub.pl 